\title{
High-Resolution Mapping of Carbon Flows in Urban Systems: A Case Study in Guangyuan, An Earthquake-Affected Mountainous City of China
}

\author{
Y. $\mathrm{Hao}^{1}$, L. X. Zhang ${ }^{1}$, Y. P. Cai ${ }^{1,2}$, M. R. Su${ }^{1}$, Z. F. Yang ${ }^{1, *}$ \\ ${ }^{1}$ State Key Laboratory of Water Environment Simulation, School of Environment, Beijing Normal University, Beijing, 100875, China \\ ${ }^{2}$ Institute for Energy, Environment and Sustainable Communities, University of Regina, Saskatchewan S4S 7H9, Canada
}

Received 14 August 2014; revised 4 September 2014; accepted 6 September 2014; published online 3 November 2014

\begin{abstract}
Being different from inventoried data, spatialized maps of carbon dioxide $\left(\mathrm{CO}_{2}\right)$ flow at high resolution in urban areas are essential for carbon cycle research and carbon reduction management. In this research, Guangyuan, a mountainous city located in southwestern China, which was heavily affected by the 2008 earthquake, was used as a studying case. In this city, gridded data of vertical carbon flows at $1-\mathrm{km}$ resolution was extracted based on point emission sources and other supporting data in Guangyuan. Among the 16,020 grids, 4,465 performed as $\mathrm{CO}_{2}$ emission sources while the other 11,555 as sinks. On the whole, Guangyuan City served as a carbon sink in 2010 , with the total net flow of $0.44 \mathrm{Mt} \mathrm{CO}_{2}$ being sequestered and stored by vegetations. The overall pattern of emission sources and sinks matched well with local land-use patterns. The hotspots of $\mathrm{CO}_{2}$ emissions appeared in the builtup areas along local valleys, as well as low mountainous areas. On the contrary, large areas of carbon sinks were mainly distributed in the mountainous areas of northwest and northeast parts of Guangyuan. With regard to the distribution of gridded emissions, an evidently clustered characteristic was identified. The proportion of the largest individual emission grid accounted for $12.01 \%$ of the total emission. The cumulative percentage of gridded emissions indicated that supervision of $0.06 \%$ of the total area could enable effective management of approximately $60 \%$ of the total emissions in Guangyuan. Thus, the spatialized gridded data of carbon flows produced in this research can provide significant policy implications for urban planning and regional carbon flow mitigation.
\end{abstract}

Keywords: carbon dioxide flux, urban systems, gridded dataset, Guangyuan City

\section{Introduction}

City is the primary energy consumer in human society, which is providing many potential opportunities for possible energy savings and carbon emission reductions (Cai et al., 2008, 2009; Zhang et al., 2014). Correspondingly, cities are practical carbon flow hubs, and are thus responsible for large amounts of carbon emission and storage. It is believed that over $80 \%$ of global carbon emissions is originating from urban areas (Churkina, 2008; Zhang et al., 2014), which comparatively occupy less than $2.4 \%$ of the total landmass (Potere and Schneider, 2007). Urban systems play a dominant role in the evolution and dynamics of global carbon cycle and would be of great significance for achieving carbon emission reduction targets in many countries and globally (Zhang et al., 2011). Urban carbon management based on the analysis of carbon cycle has thus been especially focused by a number of large- scale carbon reduction projects, attracting many efforts from research and management communities (Dhakal, 2005).

${ }^{*}$ Corresponding author. Tel.: + 861058807951 ; fax: +86 1058803006.
E-mail address: zfyang@bnu.edu.cn (Z. F. Yang).

ISSN: 1726-2135 print/1684-8799 online

(C) 2016 ISEIS All rights reserved. doi: 10.3808/jei.201400281
Therefore, it is desired to undertake accounting of carbon cycle for urban systems, particularly in emerging countries that are consuming large quantities of energy resources such as China. In China, urbanization has proceeded rapidly in the past decades and is expecting to have reached 70 to $75 \%$ by 2050 (CCRC, 2009). With rapid urbanization and industrialization in this country, $\mathrm{CO}_{2}$ emissions from cities and their shares in regional and country-wide total are definitely increasing (Feng et al., 2013). To cope with this increasing pressure and further stimulate China's economic development, identification of effective strategies for urban energy and carbon management, and undertaking systematic analysis of carbon flows in urban systems are of significant need.

Although emissions from a number of carbon sources were considered by existing literatures, there was not a clear view on carbon cycle of urban systems that could tackle carbon-related factors and processes such as storage and emission in a holistic manner (Zhao et al., 2014). In consideration of this fact, Churkina (2008) emphasized the necessity of considering both biophysical and human-related carbon fluxes through an integrated urban carbon cycle approach, significantly promoting relevant studies. Inspired by this pioneering work, recent studies in this field have attempted to simultaneously analyze carbon flows in both horizontal and vertical directions within an urban system (Zhao, 2012; Zhao and 
Huang, 2013). Christen et al. (2010) simulated carbon storage and flux at the neighborhood scale based on urban metabolism approach, and remote sensing, energy-related and emissions data. Kellett et al. (2013) used a bottom-up modeling approach to assess neighborhood-scale carbon storage, intake and export within an urban system. More recently, Hao et al. (2014) proposed a natural-social dualistic carbon cycle system.

In addition to the studies upon integrated accounting of carbon flows, temporal and spatial dimensions of carbon flows in urban areas need to be considered for providing a holistic view of urban carbon cycle. Although temporal dynamics of urban carbon cycle has been analyzed by many researchers (Hao et al., 2014; Hu et al., 2014; Huang et al., 2013; Tan et al., 2010a, b, c; Zhao, 2012; Zhao and Huang, 2013), there have been few attempts to quantify and map carbon flows at a city scale (Davies et al., 2011), which is major contribution of this paper. Comparatively, both carbon mitigation practices and research on carbon cycle and climate change modeling require carbon flow maps at enhanced accuracy and resolution (Wang et al., 2014). For instance, the gridded emission data can help policy makers properly prioritize emission control areas and facilitate the meticulous and wise management of carbon emission mitigation (Cai and Zhang, 2014). Accurate and spatially explicit emission inventories that serve to establish the baseline level of $\mathrm{CO}_{2}$ emissions and validate the extent of sources' compliance with abatement targets, play a vital role in the calibration of general circulation models that can be used to understand and predict global, national and regional climate and ecosystem dynamics, since they are fundamental inputs to carbon cycle models (Gately et al., 2013). Moreover, uncertainties of $\mathrm{CO}_{2}$ emission inventories have rarely been quantified on a gridded basis, leading to difficulties in evaluating them at the regional scale. Furthermore, mapping regional carbon emissions is challenging due to data limitations. The existing emission inventories mainly adopted several spatial proxies such as population and nightlight information to downscale data at national or provincial levels. Such procedures truly introduce errors where the proxy variables and actual emissions are weakly correlated, and thus limit analysis of the relationship between emissions and demographic trends. For instance, emission ratio per capita is not uniform, especially in many developing countries, and is thus creating spatial biases (Wang et al., 2013).

With regards to the above-mentioned concerns, the main objective of this study is to compile a $1-\mathrm{km}$ resolution map of carbon flows in urban areas of Guangyuan and to analyze the spatial characteristics of carbon cycle and balance, covering vertical and horizontal dimensions, as well as multiple factors and processes. This research can thus provide theoretical and practical guidance for urban energy management and lowcarbon energy policy formulation in different sectors of Guangyuan, and will help identify feasible strategies of sustainable development and emission reduction in this city. The method and application results can be expanded for simi- lar cities across China.

\section{Overview of Guangyuan City}

Guangyuan, a mountainous city, is located at northern Sichuan province, containing large areas of forest and farmland (Figure 1). It is the intersection area of Micang Mountains, Longmen Mountain and the low mountainous area in northern Sichuan Basin. To the north of the city are mountainous areas with higher altitude, while the south is hilly with lower altitude. One of the tributaries of the Yangtze River, Jialingjiang River flows through the city. Its administration division involves 7 districts and counties (i.e., districts of Lizhou, Yuanba, Chaotian, and counties of Wangcang, Qingchuan, Jiange, and Cangxi). In 2012, the population was 3.12 million. GDP per capita reached 2,386 US Dollars. The primary, secondary, and tertiary industries accounted for 20,47 , and $33 \%$ of the total GDP, respectively. Guangyuan's economy is based on a diverse array of heavy industries, as well as mining and agriculture (Guan and Barker, 2012). It was one of the epicenters of an 8.1-magnitude earthquake and aftershocks in the 2008's Wenchuan earthquake. With regard to the post-earthquake reconstruction, fossil energy consumptions and the corresponding carbon emissions and intake in Guangyuan are definitely increasing. On the contrary, as a mountainous city with high proportion of forest coverage, it is an important carbon sink. Identification of developing strategies is thus very critical to Guangyuan City that is currently under rapid urbanization in West China, which is under double challenges of economic development and carbon emission reduction. This makes $\mathrm{Gu}-$ angyuan as a desired studying case for carbon cycle analysis. Through undertaking carbon flow mechanism analysis based on comprehensive pointed emission dataset, a carbon flowmap has been established for Guangyuan urban system at 1$\mathrm{km}$ resolution.

\section{Methodology}

\subsection{Research Framework and Scope Definitions}

As an open social-economic system, there are huge carbon flows and exchanges within and outside of an urban system (Vaccari et al., 2013). Within such system, a lot of activities are also responsible for carbon such as generation, transform, decomposition, and transfer. Moreover, carbon can be imported from and exported to the surrounding areas. In order to reflect and tackle such complexities, a comprehensive accounting framework for urban carbon cycle has been established in the previous paper by Hao et al. (2014). Such a framework can be characterized by multi-dimensional features, including vertical and horizontal carbon fluxes (Churkina, 2008). The land-atmospheric $\mathrm{CO}_{2}$ flux represents net $\mathrm{CO}_{2}$ emission that is the balance of fossil fuel induced emissions and carbon storage by various terrestrial systems (i.e., residual terrestrial sink). 


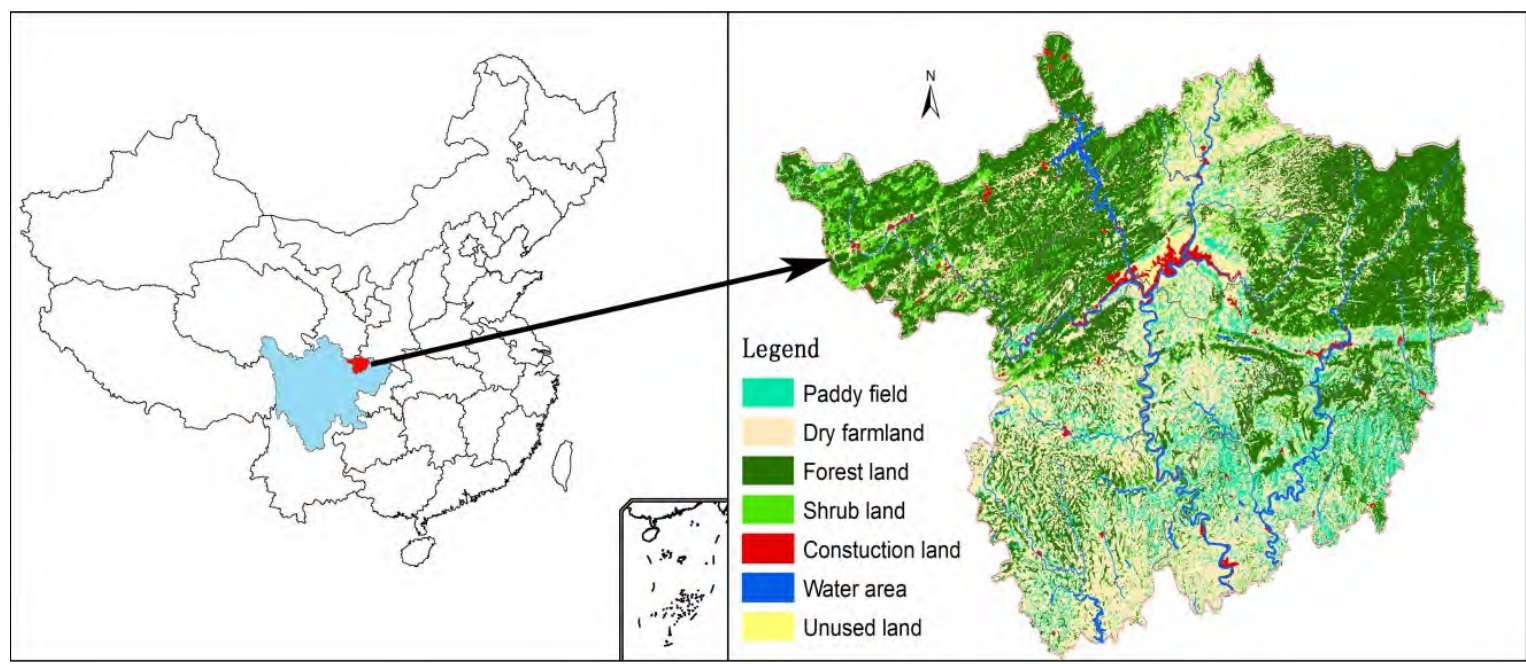

Figure 1. The location and land-use types of Guangyuan City in Sichuan Province, China.

Natural origin carbon fluxes are mainly related to vegetation due to its photosynthesis and respiration. The vertical fluxes of anthropogenic origin are mainly produced from fossil fuel combustion, waste decomposition, and directly human breath. Horizontal fluxes of carbon are mostly driven by human activities. These fluxes include transfer of food and fiber from agricultural and forest products to urban systems, as well as trash flows from urban to relevant facilities such as landfilling sites. To account for the multi-dimension features of carbon flows, three scopes (i.e., scopes 1 to 3 ) were conventionally proposed as the system boundary for direct and indirect $\mathrm{CO}_{2}$ emissions (Folke etal., 1997; Churkina, 2008). Scope 1 covers all direct emissions that occur within the territorial boundary of the city. Scope 2 covers indirect emissions that occur outside of the city boundary, which are mainly due to electricity consumptions, district heating and cooling. Comparatively, scope 3 covers the rest of emissions that occur outside the city boundary, mainly including electricity transmission and distribution losses, as well as embodied emissions in imported fuels and goods (ICLEI and C40, 2012; UNEP et al., 2010). Generally speaking, it is nearly impossible to represent all these flows through a map due to data availability and computational requirements. In this research, merely the vertical dimension of carbon flow is considered, i.e., the emissions discharged into the air and $\mathrm{CO}_{2}$ sequestered and stored by vegetation in the city. Specifically, with regard to $\mathrm{CO}_{2}$ emission accounting, scope 1 was involved. Comparatively, scopes 2 and 3 are not covered due to the fact that Guangyuan is a net electricity exporter without cross-cityborder supplies of heating and cooling.

\subsection{Data Source}

In this research, the following major data sources were employed: (a) detailed information and data of energy consumptions in 346 enterprises and clinker production plants, coke and carbonate utilization, and iron steel production plants, carbon contents in iron and steel industries. They were mainly derived from The First China Pollution Source Census (FCPSC) database.The FCPSC database in China provides a valuable basis to produce bottom-up emission maps based on detailed point emission source inventories (Cai and Zhang, 2014). It is China's first nationwide survey of all types of energy consumptions, categorized by combustion fuels and industrial feedstock in facilities with spatial coordinates (Wang et al., 2014); (b) information and data of the residential sector, including energy use from hotels, restaurants, hospitals, schools, and household. Those were obtained from district/ county-level FCPSC; (c) information and data of energy consumptions in agricultural and transportation sectors. They were acquired from governmental statistics and reports such as the Guangyuan Statistical Yearbook (GYSY, 2011); and (d) information and data regarding land use. They were obtained through interpreting Landsat TM (http://landsat.usgs.gov/) imagery with necessary corrections and validations. Based on the above-mentioned information and data, $\mathrm{CO}_{2}$ emissions were calculated through the summation of the total output emissions due to fossil fuel consumptions. For instance, in terms of $\mathrm{CO}_{2}$ emissions from the industrial sector, industries of cement, lime, iron and steel, glass and ammonia productions were considered in this research. The corresponding emission factors were extracted from IPCC reports (IPCC, 2006). As to the calculation of carbon sinks, land use data was used to account for the emissions due to inspiration and absorption of vegetation photosynthesis. Detailed process of calculation was reported by the previous research by Hao et al. (2014)

\subsection{Method of Spatialization}

The gridded carbon flow data in Guangyuan at 1-km resolution were established in the following steps: 1) based on a GIS platform, the total 16,020 girds were created, 2) regarding the point emission sources in the city, a number of dots were used according to their coordinates and the corresponding amount of $\mathrm{CO}_{2}$ emissions (from processes of energy 
consumptions and industrial productions). Then, the summation of point source $\mathrm{CO}_{2}$ emissions from relevant dots within a grid can be considered as the total for the grid. As a undeveloped city, there are 346 enterprises in Guangyuan, and all of them were considered in this research, 3) the total carbon emissions associated with transportation was allocated to the $4,544 \mathrm{~km}$ road line through assigning weights according to road types (e.g. express way, and the first- to the thirdgrade highway), 4) in terms of the agricultural sector, the total sectoral $\mathrm{CO}_{2}$ emission of the entire study area was divided into every county/district proportionally to their agricultural population. Then $\mathrm{CO}_{2}$ emissions were generated based on the number of grids in the county/district and the corresponding emission statistics, 5) the urban commercial/residential energy consumption consisted of energy use from hotels, restaurants, hospitals, schools, and household. For further spatialization to values at the $1-\mathrm{km}$ resolution, population were used as proxy to allocate thed istrict/county level emissions to each grid. Since the population grid dataset was of significance for $\mathrm{CO}_{2}$ emission spatialization, the Data Sharing Infrastructure of Earth System Science of China were adopted, which has produced China's 1-km gridded population data in 2003 and were proved to be reliable (Cai et al., 2012; Jiang et al., 2002). In this research, the population grid data from 2003 to 2010 was updated, and up-scaled to $1-\mathrm{km}$ resolution, 6) the carbon sink by vegetation was calculated and mapped using land use data, involving the contribution of multiple land use types, and 7) the $\mathrm{CO}_{2}$ emissions from the industrial, agriculture/rural household, urban residential and commercial, and transportation sectors, as well as relevant carbon sink were summed in every grid to complete the overall gridded $\mathrm{CO}_{2}$ carbon flow in vertical dimension of Guangyuan City.

\section{Results and Discussion}

\subsection{Carbon Emission Sources and Sinks}

As a carbon emitter, the total carbon emission of Guangyuan was 4.22 million metric tons in 2010. Emission per capita emission was $1.38 \mathrm{t}$, which was much lower than many cities in China (Cai and Zhang, 2014; Kennedy et al., 2012; Zhao et al, 2014). The emissions from point and areal sources accounted for 54 and $32 \%$ of the total, respectively. The transportation sectors accounted for $14 \%$ of the total emission. The predominant point emissions and the industrial proportion of the total emissions reflected that Guangyuan was in the premature stage of urbanization and industrialization in 2010, which was also stated by many researchers (Guan and Barker, 2012).

With regards to the spatial distribution of $\mathrm{CO}_{2}$ emission in the city, three maps have been generated, covering point, line and areal emission sources. As indicated in Figure 2, the direct $\mathrm{CO}_{2}$ emission from point sources was aggregated to $2.26 \mathrm{Mt}$. Also, it can be calculated that the $\mathrm{CO}_{2}$ emissions derived from fuel combustion and industrial processes were 2.02 and $0.24 \mathrm{Mt}$, accounting for 89 and $11 \%$ of the total point emissions, respectively. Among the $\mathrm{CO}_{2}$ emissions from fuel consumptions, combustion of coal, oil and natural gas were responsible for $71.64,24.17$ and $4.19 \%$, respectively. The majority of high-emission point sources were mainly distributed in Lizhou and Wangcang districts that are along the piedmont valley (i.e., Mi-cang Corridor).

The industrial point source emissions from those two districts/counties approximately contributed to $60 \%$ of the total point emission in Guangyuan City. Comparatively, the gross industrial outpute in those two counties merely accounted for $24 \%$ of the total in this city. They suffered from the largest carbon emission intensity in the city, representing over $3 \mathrm{t}$ per $10^{4} \mathrm{RMB}$ output. The main reason for this was the existence of two major coal mining sites with a number of carbon-intensive enterprises, power plants, and cement factories.

Using the above-mentioned method, on-road $\mathrm{CO}_{2}$ emissions were estimated for each $1-\mathrm{km}$ section of major roads in Guangyuan City. These gridded results showed the strong influence on emissions of urban areas as well as highways across the city (Figure 3). For instance, the formation of a higher $\mathrm{CO}_{2}$ emission belt extending from northeast to

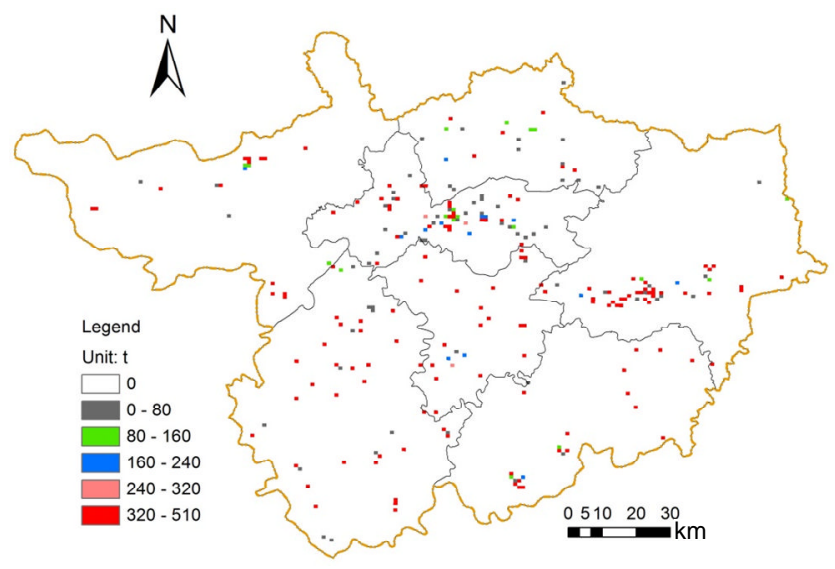

Figure 2. Spatialized $\mathrm{CO}_{2}$ emissions from point sources in Guangyuan City.

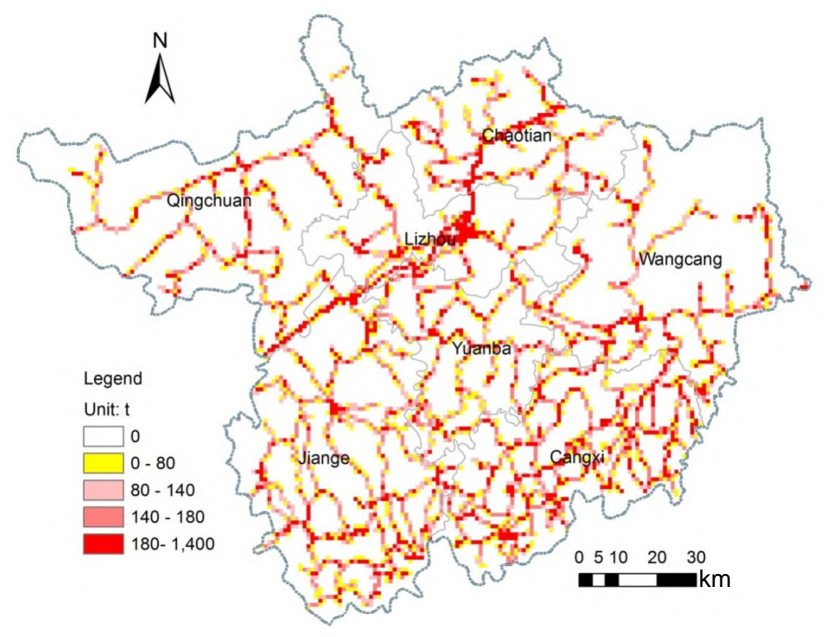

Figure 3. On-road $\mathrm{CO}_{2}$ emissions in Guangyuan City. 
southwest can be attributed to a higher transportation capacity due to the existence of urban district roads and state G5 expressway (i.e., the Jing-Kun expressway, from Beijing to Kunming). The total of $\mathrm{CO}_{2}$ emission associated with transportation sector was $0.61 \mathrm{Mt}$.

In this city, areal source of $\mathrm{CO}_{2}$ emissions include those derived from energy consumptions by various agricultural activities, as well as residential energy consumption in rural and urban areas. Similar to the point source emissions, the distribution of areal source $\mathrm{CO}_{2}$ emissions was largely affected by surface land-use features. The high emission areas were in accordance with the Micang Corridor due to intensive agricultural activities and large population. In addition to the Micang Corridor, the southern areas of Guangyuan, i.e., the Jiange and Cangxi counties also had relatively high emission densities due to intensive agricultural activities. On the contrary, the mountainous areas with good vegetation coverage contributed a minor part to the areal source emissions. Totally, the areal source $\mathrm{CO}_{2}$ emissions reached $1.35 \mathrm{Mt}$, slightly less than that of the point source emissions (Figure 4).

In contrast to the emission profile of $\mathrm{CO}_{2}$, the carbon sink of Guangyuan is highly related to its land use patterns. The areas with higher sink capability were definitely in accordance with vegetation coverage (i.e., the mountainous areas in the northeast and northwest of Guangyuan). In an aggregated sense, the total carbon uptake by vegetation in Guangyuan within an individual year was approximately $4.65 \mathrm{Mt}$, which was slightly higher than the total emissions. Generally, the temperate mixed broadleaf-conifer forests in the mountainous areas play a predominant role in offsetting the $\mathrm{CO}_{2}$ emission to the atmosphere (Figure 5).

\subsection{Net Carbon Flow}

In consideration of vertical emissions and sinks in Guangyuan City, the spatial distribution of net carbon flow was produced and shown in Figure 6. Detailed accounting results with regard to different districts/counties are listed in Table 1.

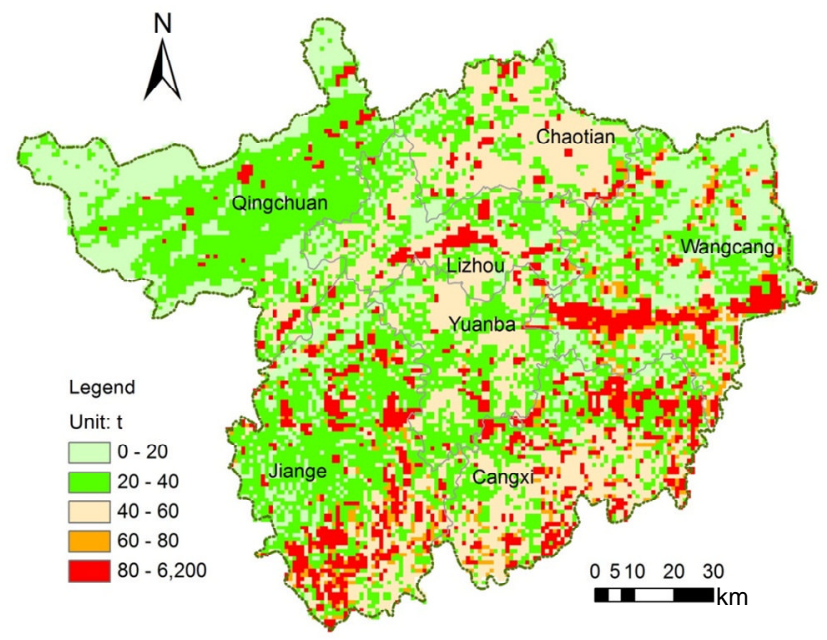

Figure 4. Distribution map of $\mathrm{CO}_{2}$ emissions from areal source.

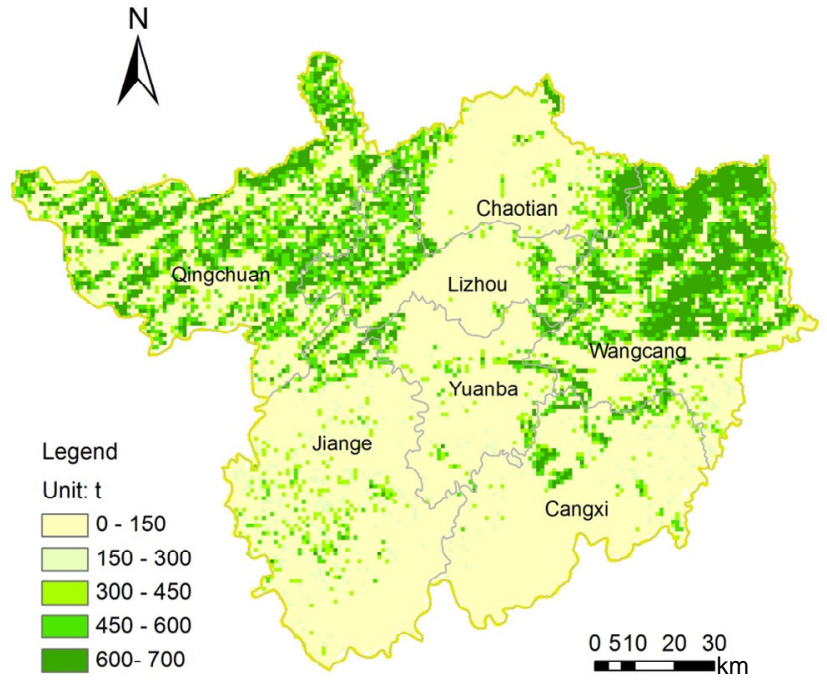

Figure 5. Carbon sinks by vegetation in Guangyuan City.

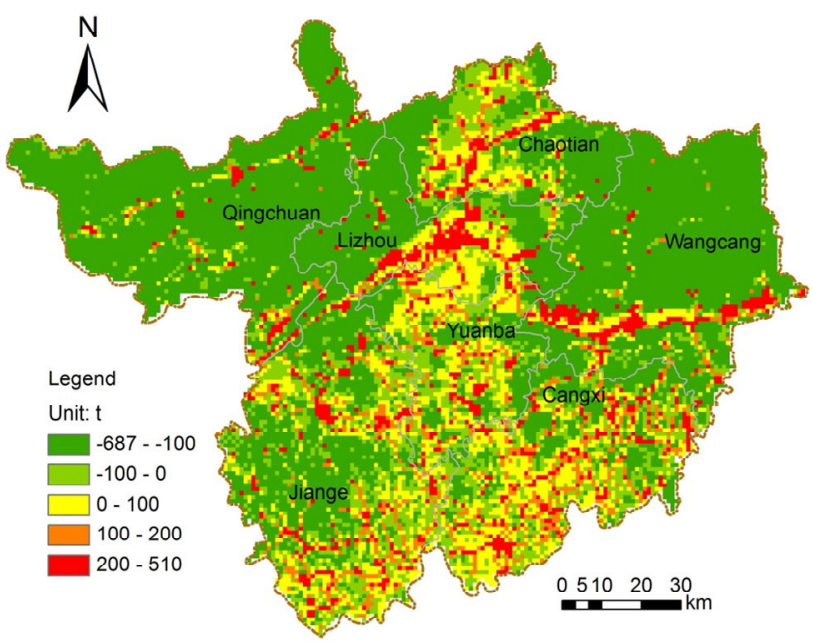

Figure 6. Map of balanced carbon flow in Guangyuan City.

Among the 16,020 grids, 4,465 of them performed as the sources while 11,555 as sinks. On the whole, Guangyuan City served as a net carbon sink in 2010, with the total net flow of $0.44 \mathrm{Mt} \mathrm{CO}_{2}$ that was mainly absorbed by vegetation. Among the 7 districts/counties, four of them served as carbon sinks. Comparatively, three of them performed as net carbon emitters. Lizhou, the central urban district, undoubtedly was the largest carbon emitter with $0.5 \mathrm{Mt}$ net vertical emissions. On the contrary, Qingchuan County was the largest carbon sink with the contribution of $1.14 \mathrm{Mt} \mathrm{CO}_{2}$ to the total emission in Guangyuan offset. As shown in Figure 6, the built-up area matched well with the hotspots of $\mathrm{CO}_{2}$ emissions. It is important to note that the intensive $\mathrm{CO}_{2}$ emissions dominantly happened along the Micang Corridor, mainly due to urban expansion and industrial development within such a belt. In the mountainous areas of Guangyuan, there was a high vegetation coverage and therefore served as major carbon sink. In 
Y. Hao et al. / Journal of Environmental Informatics 27(2) 106-115 (2016)

Table 1.The Accounting Results of Vertical Carbon Emission and Sink in Guangyuan for Different Districts (unit: Mt)

\begin{tabular}{|c|c|c|c|c|c|}
\hline \multirow{2}{*}{ District } & \multicolumn{3}{|c|}{ Source } & \multirow{2}{*}{$\begin{array}{c}\text { Sink } \\
\text { Soil and vegetation }\end{array}$} & \multirow{2}{*}{ Net flow } \\
\hline & Industrial point source & Traffic line source & Area source & & \\
\hline Qingchuan & 0.03 & 0.07 & 0.15 & -1.40 & -1.14 \\
\hline Jiange & 0.06 & 0.13 & 0.28 & -0.57 & -0.10 \\
\hline Yuanba & 0.04 & 0.06 & 0.10 & -0.21 & -0.01 \\
\hline Chaotian & 0.68 & 0.06 & 0.12 & -0.38 & 0.48 \\
\hline Wangcang & 0.68 & 0.08 & 0.24 & -1.31 & -0.31 \\
\hline Cangxi & 0.15 & 0.13 & 0.19 & -0.33 & 0.14 \\
\hline Lizhou & 0.61 & 0.07 & 0.27 & -0.45 & 0.50 \\
\hline Guangyuan & 2.26 & 0.61 & 1.35 & -4.65 & -0.44 \\
\hline
\end{tabular}

the mountainous area of north and plain areas of southern Guangyuan, most of the grid performed as carbon source, due to high population density and intensive human activities.

With regards to the districts/counties level, the high $\mathrm{CO}_{2}$ emission per capita in Chaotian (3.75 t), Lizhou (1.85 t), and Wangcang (1.82 t) districts were mainly due to the associated energy-intensive industries. However, Cangxi and Jiange $(0.41 \mathrm{t})$, and Qingchuan $(0.49 \mathrm{t})$ were all at relative lower levels in terms of $\mathrm{CO}_{2}$ emissions per capita.

Accordingly, in terms of the carbon sink profiles in Guangyuan City, Qingchuan was the primary contributor. Comparatively, Jiange County made the least contribution. Therefore, Qingchuan County was the largest contributor to offsetting carbon emissions in Guangyuan City. On the other side, Chaotian serviced as the largest carbon emitter among the 7 districts/counties in Guangyuan City.

\subsection{Discussions}

To further explore the spatial distributions of $\mathrm{CO}_{2}$ emissions and uptake among the grids of Guangyuan City, histogram of these two carbon fluxes in grids associated with the 7 districts/counties as well as the entire city is shown in Figures 8 and 9. In the entire city, carbon emissions in the grids with regard to the different boundaries had the lognormal distributions and Gaussian spectrums. However, there were two evi-

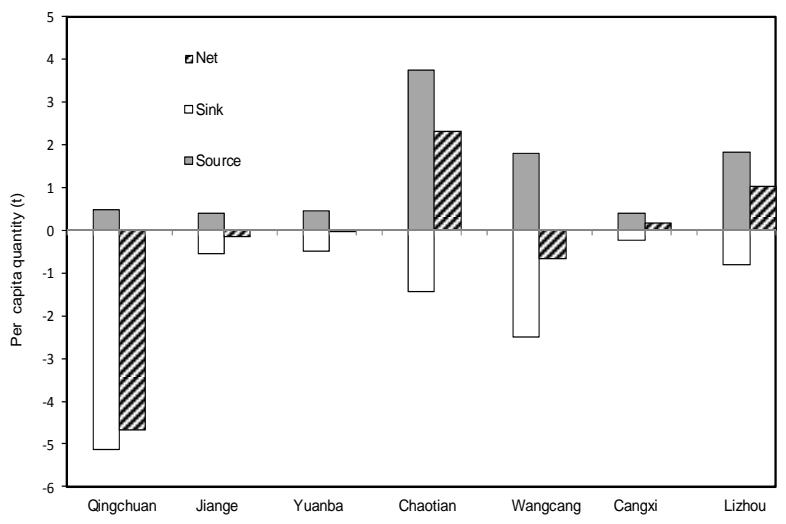

Figure 7. The profile of $\mathrm{CO}_{2}$ emissions and uptake per capita in Guangyuan City. dent peaks in the histogram distributions of Qingchuan County. The formation of the first peak was due to the large quantity of low-value grids. This distribution pattern reflected the inner uneven distribution and large gaps in $\mathrm{CO}_{2}$ emissions in the grids of Qingchuan County because there were large numbers of grids with large-area of vegetation covers. Another county with two emission peak values was Cangxi, reflecting the land-use patterns of many scattering small-scale townships and intensive farming activities in this county. The lognormal distribution of $\mathrm{CO}_{2}$ emissions in grids of Lizhou, Yuanba and Chaotian as well as the entire Guangyuan showed that the emission source patterns were evenly distributed, which was highly related to the ongoing urbanization process. In contrast to the distribution of carbon emissions, the distribution of carbon uptake among grids was diversified, which to large extent reflected the land use patterns among the 7 districts/counties. For instance, the increasing tendency of $\mathrm{CO}_{2}$ uptake in Qingchuan implied high forest coverage and low urbanization ratio in this county. Evidently, in the figure of Lizhou district, many grids had relatively low $\mathrm{CO}_{2}$ uptaking amounts, indicating high urbanization ratio and low carbon sequestration ability in this district. Cangxi country is characterized by extensive agricultural activities with less areas of forests and therefore is lacking of carbon uptake capability.

The mapping of vertical carbon flow combing source and sink provided many options for effective carbon management and sound policy formulation. As shown in previous results, the distribution of emissions and sinks showed a great spatial heterogeneity, especially for the emissions. That is to say, the contribution of the grids to the total amount emission differed greatly. Figure 10 shows the cumulative curve of the grids that contributed to the total emission and absorption. As indicated by Figure 10(a), there is a high degree of emission clustering. The individual grid with the largest emission contributed to $12.01 \%$ of total. Accumulated emissions of the top 10 grids accounted for $38.99 \%$ of total. Moreover, emissions of the top 100 grids accounted for $55.87 \%$ of the total. The emission map indicated that the supervision of $0.06 \%$ of the total land could enable the management of approximately $60 \%$ of emissions in Guangyuan. This is very meaningful for the government of Guangyuan to reallocate their monitoring and enforcement of emission reduction quotas among the grids, and put focused financial and human resources into these top 

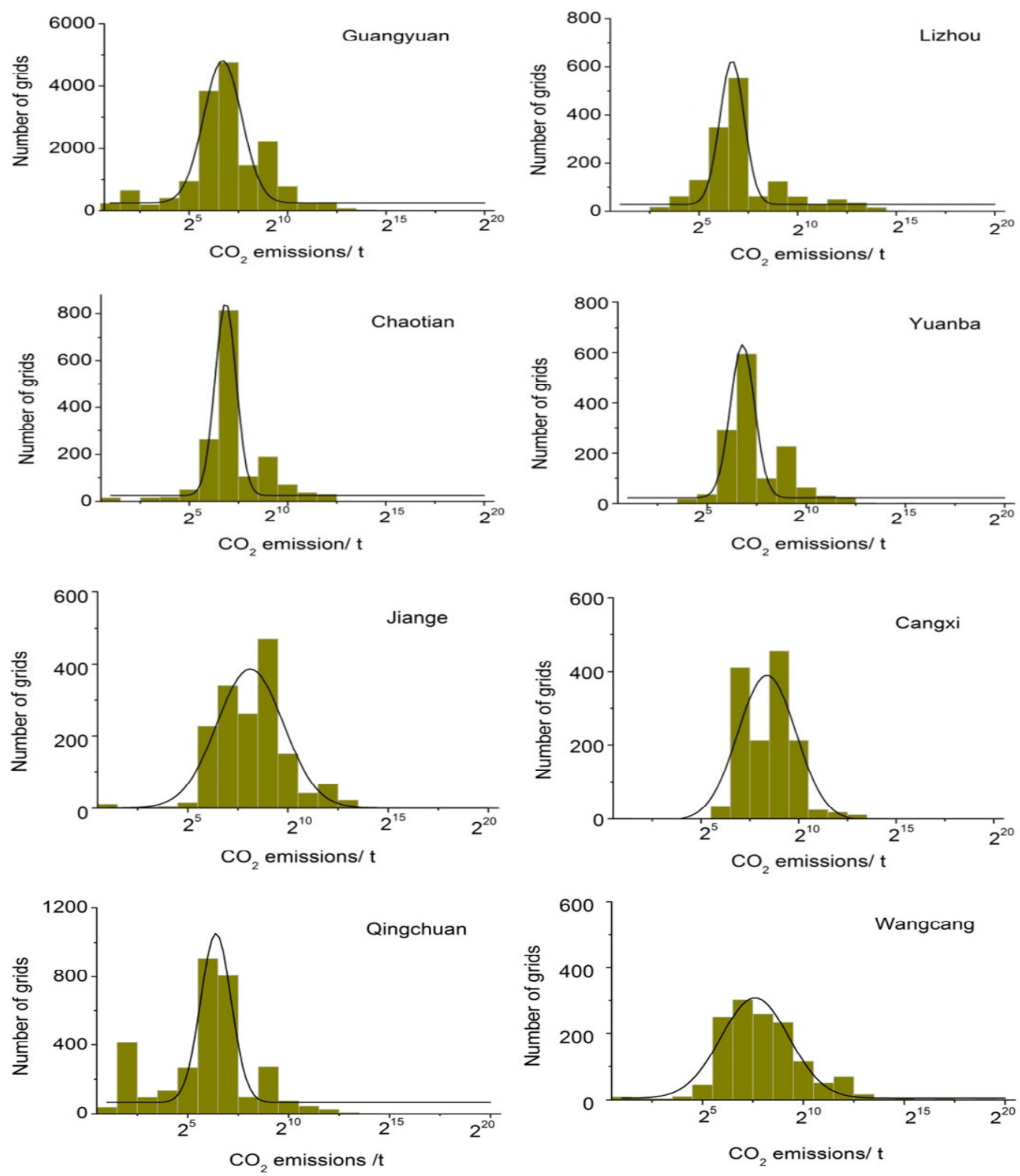

Figure 8. Histogram statistics for $\mathrm{CO}_{2}$ emissions in grids associated with the 7 districts/counties and the entire Guangyuan City.

100 grids. In contrast, the cumulative curve of carbon sink by the grids seems to have less spatial heterogeneity (i.e. distributed evenly). It is worthwhile to note that the $\mathrm{x}$-axes of Figure 10(a) and (b) are different. One was logarithmic coordiates and the other was linear coordinates. Nevertheless, there was also clustering characteristics with regard to $\mathrm{CO}_{2}$ absorption among those grids. Approximately 7,300 grids accounted for $80 \%$ of the $\mathrm{CO}_{2}$ sink, where the remaining $20 \%$ emissions were shared by the other half of the total grids (i.e., approximately 9,300 grids).

Definitely, the high resolution $\mathrm{CO}_{2}$ emissions dataset of Guangyuan is of significance to carbon reduction management in local areas. It could provide solid foundation for the comparison and benchmark settlement between many districts. For instance, the gridded data build up a uniform data platform for regional $\mathrm{CO}_{2}$ emission estimation and comparison, and therefore were essential to the burden sharing of $\mathrm{CO}_{2}$ emission reduction and the joint control and mitigation of $\mathrm{CO}_{2}$ emissions. For city like Guangyuan, it can be easy to devise a framework for ecological compensation due to the different roles in carbon emission and abatement, based on such high resolution gridded data of carbon emissions and absorptions. If decision makers intend to balance the financial income from penalty due to carbon emission, a virtual accounting can be undertaken for all the grids or other regional boundaries. Once the price of $\mathrm{CO}_{2}$ emission $(p)$ is determined, the 

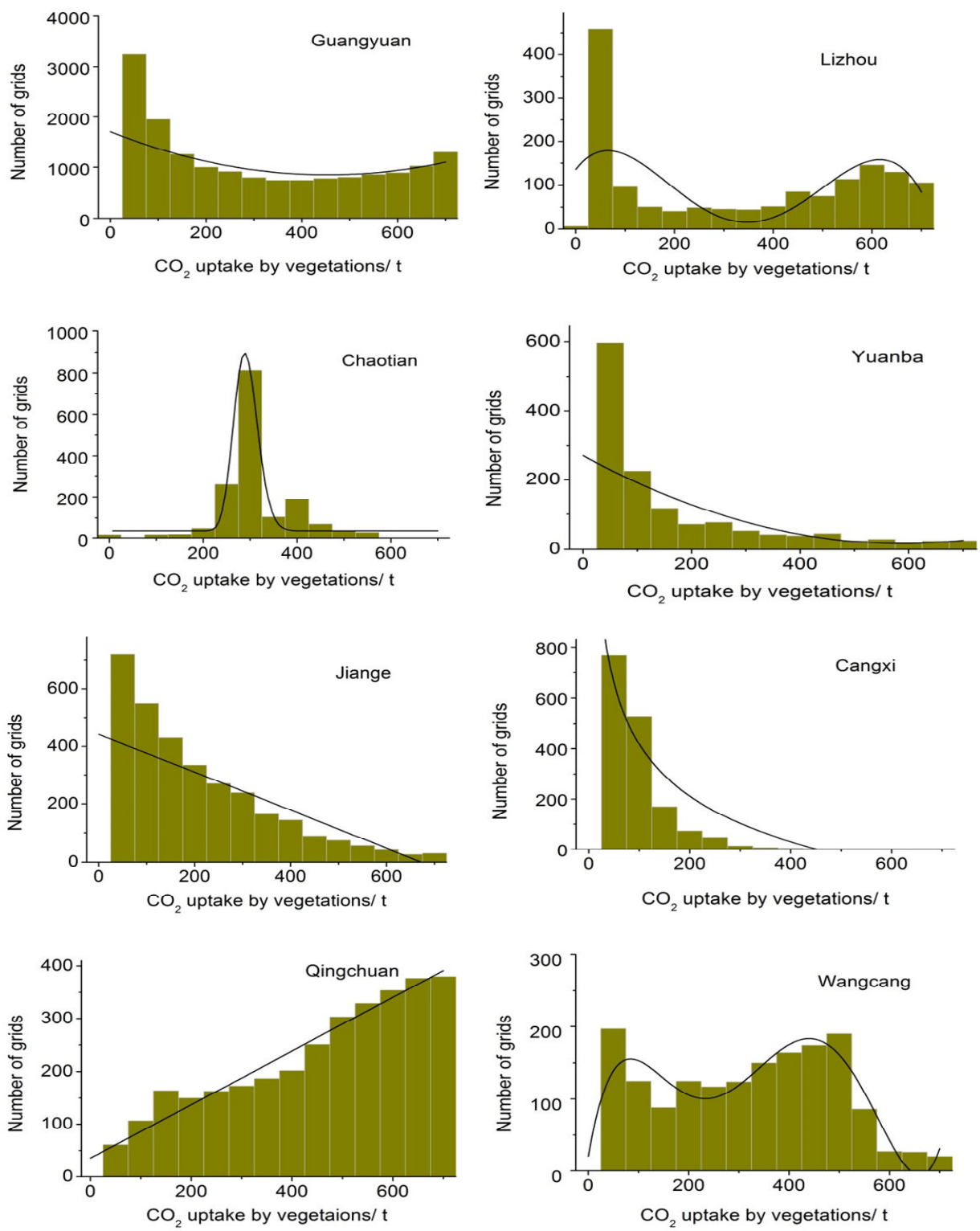

Figure 9. Histogram statistics for $\mathrm{CO}_{2}$ uptake in grids of the 7 districts/ counties and the entire Guangyuan City.

accounting could represent relevant funds from grids (i.e., $\Sigma p^{*} e_{i}, e_{i}$ is the total emission of grid $\left.i\right)$. Then the funds can be reallocated to each grid according to their contributions to provide carbon offsetting roles (i.e., $\left(\Sigma p^{*} e_{i} / \Sigma s_{j}\right) * s_{j}, s_{j}$ is the total carbon absorbed by grid $\mathrm{j}$ ). For each grid, the fund flow would thus be $p^{*}\left(e_{i}-e_{s}\right)$. The positive value means it needs to pay a certain amount of money to the virtual account or to other grids. Comparatively, the negative value means it could get a certain amount of money from the neighboring grids due to its good performance in balancing carbon flow.

\section{Concluding Remarks}

Based on a GIS platform, a spatialized carbon dioxide
$\left(\mathrm{CO}_{2}\right)$ flow map was developed in this research through addressing vertical $\mathrm{CO}_{2}$ emissions derived from energy consumptions, industrial processes and vegetation uptake at 1-km resolution in Guangyuan City. The results showed that 4,465 grids performed as the sources while 11,555 as sinks among the total 16,020 grids. The results illustrated that Guangyuan City was a net carbon sink when balancing emission through economic activities and uptake by vegetation (the net total flow of $0.44 \mathrm{Mt} \mathrm{CO}_{2}$ was sequestered and stored by vegetation in 2010). With regard to $\mathrm{CO}_{2}$ emissions among all of the grids, the individual grid with the largest emission contributed to $12.01 \%$ of total. The accumulated emissions of the top 10 grids accounted for $38.99 \%$ of the total. The emissions of the top 100 grids accounted for $55.87 \%$ of the total. This pattern 
(a) carbon emissions by grids

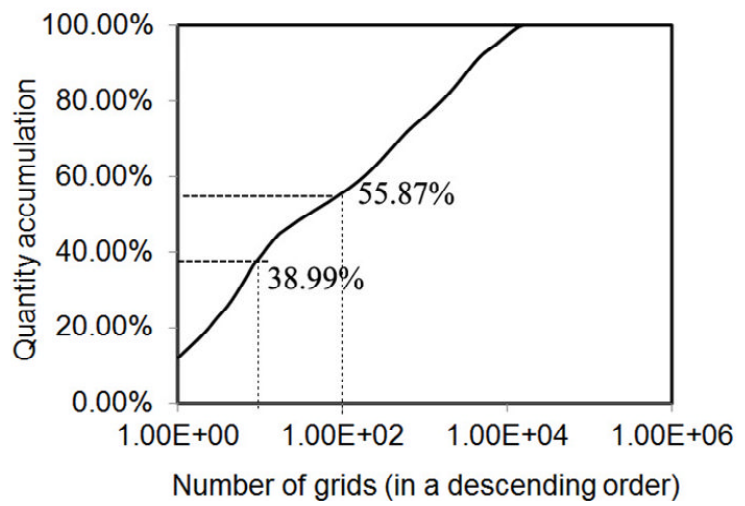

(b) carbon uptake by grids

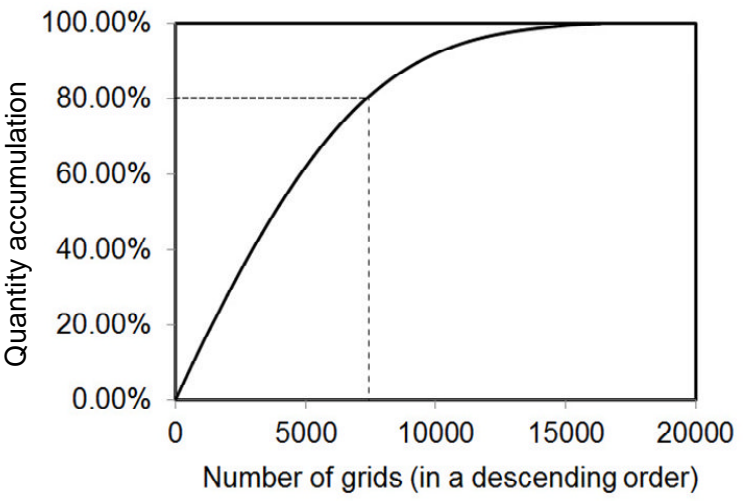

Figure 10. Cumulative percentage of total quantities: (a) carbon emissions by grids, (b) carbon uptake by grids. The grids were ranked the first in terms of emission by descending order before the cumulative percent calculation.

would be of great significance to local decision makers, i.e., the supervision of $0.06 \%$ of the total grids could achieve effective management of approximately $60 \%$ of emissions in the city. The significant difference in $\mathrm{CO}_{2}$ emissions between urban and rural areas in China's western city like Guangyuan suggested that further studies on effects of rapid urbanization upon $\mathrm{CO}_{2}$ emissions should be addressed.

As a step forwards to urban carbon emission inventory and combination of sources and sinks, this research represented an integrated view of urban carbon flow with high spatial resolution at $1 \mathrm{~km}$. The methodology can be applicable to many similar Chinese cities. Those cities have great potential in $\mathrm{CO}_{2}$ emissions reduction and have been recognized as the major possible reduction sources. The gridded data could be used to develop a uniform data platform for $\mathrm{CO}_{2}$ emission estimation and comparison in cities, which could reduce spatial bias for IPCC $\mathrm{CO}_{2}$ analysis.

As for Guangyuan City, which is located in southwest China, an undeveloped region in China, in which Gross Domestic Production (GDP) per capita is only one-third of China's average, many challenges would be tackled for future development in this city. On one hand, Guangyuan needs to promote urbanizetion and industrialization for achieving economic development goals. On the other hand, to maintain a carbon sink area would be essential to both Guangyuan City and the entire China. Definitely, Guangyuan could not identify solution of giving attentions to these two or more issues if it would follow the development road of coastal regions in east China. Currently, low carbon development in China is considered as a necessary process of low carbon transformation for all cities. Then each city or every type of city should identify their own pathway for low carbon development, which would be significant to global $\mathrm{CO}_{2}$ reduction.

Acknowledgments. This work has been supported by the National Science Foundation for Innovative Research Group (No. 51121003), and the International Science and Technology Cooperation Program of China (No. 2011DFA72420). We would also like to express our gratitude to the anonymous reviewers and the editors for their comments and suggestions in improving the quality of our paper.

\section{References}

Cai, B.F., and Zhang, L.X. (2014). Urban $\mathrm{CO}_{2}$ emissions in China: Spatial boundary and performance comparison. Energy Policy, 66, 557-567. http://dx.doi.org/10.1016/j.enpol.2013.10.072

Cai, B., Yang, W., Cao, D., Liu, L., Zhou, Y., and Zhang, Z. (2012). Estimates of China's national and regional transport sector $\mathrm{CO}_{2}$ emissions in 2007. Energy Policy, 41, 474-483. http://dx.doi.org/ 10.1016/j.enpol.2011.11.008

Cai, Y.P., Huang, G.H., Yang, Z.F., Lin, Q.G., Bass, B., and Tan, Q. (2008). Development of an optimization model for energy systems planning in the Region of Waterloo.Int. J. Energy Res., 32(1), 988-1005. http://dx.doi.org/10.1002/er.1407

Cai, Y.P., Huang, G.H., Lin, Q.G., Nie, X.H., and Tan, Q. (2009). An optimization-model-based interactive decision support system for regional energy management systems planning under uncertainty. Expert Syst. Appl., 36(2), 3470-3482. http://dx.doi.org/ 10.1016/j. eswa.2008.02.036

China City Research Committee (CCRC) (2009). China's LowCarbon Eco-City Development Strategy, China City Press, pp. 78.

Christen, A., Coops, N.C., Kellett, R., Crawford, B., Heyman, E., Olchovski, I., Tooke, R., and van der Laan, M. (2010). A LiDARBased Urban Metabolism Approach to Neighborhood Scale Energy and Carbon Emissions Modeling, University of British Columbia, 2010 Technical report prepared for Natural Resources Canada.

Churkina, G. (2008). Modeling the carbon cycle of urban systems. Ecol. Model., 216(2), 107-113. http://dx.doi.org/10.1016/j.ecol model.2008.03.006

Davies, Z.G., Edmondson, J.L., Heinemeyer, A., Leake, J.R., and Gaston, K.J. (2011). Mapping an urban ecosystem service: Quantifying above-ground carbon storage at a city-wide scale. J. Appl. Ecol., 48(5), 1125-1134. http://dx.doi.org/10.1111/j.1365-2664.20 11.02021.x

Dhakal, S. (2005). The global carbon project and urban and regional carbon management. http://www.gcp-urcm.org/files/A20060904/d hakal.pdf.

Feng, Y.Y., Chen, S.Q., and Zhang, L.X. (2013). System dynamics modeling for urban energy consumption and $\mathrm{CO}_{2}$ emissions: $\mathrm{A}$ 
case study of Beijing, China. Ecol. Model., 252, 44-52. http://dx. doi.org/10.1016/j.ecolmodel.2012.09.008

Folke, C., Jansson, A., Larsson, J., and Costanza, R.(1997). Ecosystem appropriation by cities. Ambio, 26, 167-172.

Gately, C.K., Hutyra, L.R., Wing, I.S., and Brondfield, M.N. (2013). A bottom up approach to on-road $\mathrm{CO}_{2}$ emissions estimates: Improved spatial accuracy and applications for regional planning. Environ. Sci. Technol., 47, 2423-2430. http://dx.doi.org/10.1021/ es304238v

Guan, D., and Barker, T. (2012). Low-carbon development in the least developed region: A case study of Guangyuan, Sichuan province, southwest China. Nat. Hazards, 62, 243-254. http://dx. doi.org/10.1007/s11069-011-9993-3

GYSY (2011). Guangyuan Statistical Yearbook. Guangyuan Statistics Intranet.

Hao, Y., Su, M.R., Zhang, L.X., Cai, Y.P., and Yang, Z.F.(2014). Integrated accounting of urban carbon cycle in Guangyuan, a mountainous city of China: The impacts of earthquake and reconstruction. J. Cleaner Prod., in press. http://dx.doi.org/10.10 16/ j.jclepro.2014.05.091

Hu, Q., Huang, G.H., Cai, Y.P., and Sun, W. (2014). Planning of electric power generation systems under multiple uncertainties and constraint-violation levels. J. Environ. Inf., 23(1), 55-64.http://dx. doi.org/10.3808/jei.201400257

Huang, W., Dai, L.M., Baetz, B.W., Cao, M.F., and Razavi, S. (2013). Interval binary programming model for noise control within an urban environment. J. Environ. Inf., 21(2), 93-101.

ICLEI, and C40 (2012). Global protocol for community-scale GHG emissions (GPC).

IPCC (2006). 2006 IPCC Guidelines for National Greenhouse Gas Inventories. http://www.ipcc-nggip.iges.or.jp/public/2006gl/voll.ht $\mathrm{ml}$.

Jiang, D., Yang, X., Wang, N., and Liu, H. (2002). Study on spatial distribution of population based on remote sensing and GIS. Adv. Earth Sci., 17, 734-738.

Kellett, R., Christen, A., Coops, N.C., van der Laan, M., Crawford, B., Tooke, T.R., and Olchovski, I. (2013). A systems approach to carbon cycling and emissions modeling at an urban neighborhood scale.Landscape Urban Plann., 110, 48-58. http://dx.doi.org/10. 1016/j.landurbplan.2012.10.002

Kennedy, C., Demoullin, S., and Mohareb, E. (2012). Cities reducing their greenhouse gas emissions. Energy Policy, 49, 774-777. http://dx.doi.org/10.1016/j.enpol.2012.07.030

Potere, D., and Schneider, A. (2007).A critical look at representations of urban areas in global maps. Geogr. J., 69, 55-80.

Tan, Q., Huang, G.H., and Cai, Y.P. (2010a). A superiority-inferioritybased inexact fuzzy stochastic programming approach for solid waste management under uncertainty. Environ. Model.Assess., 15(5), 381-396. http://dx.doi.org/10.1007/s10666- 009-9214-6

Tan, Q., Huang, G.H., and Cai, Y.P. (2010b). Waste management with recourse: An inexact dynamic programming model containing fuzzy boundary intervals in objectives and constraints. J. Environ. Manage., 91(9), 1898-1913. http://dx.doi.org/10.1016/j.jenvman. 2010.04.005

Tan, Q., Huang, G.H., and Cai, Y.P. (2010c). Identification of optimal plans for municipal solid waste management in an environment of fuzziness and two-layer randomness.Stochastic Environ. Res. Risk Assess., 24(1), 147-164. http://dx.doi.org/10.1007/s00477-009-030 7-1

UNEP, UN-HABITAT, and Bank, T.W. (2010). International Standard for Determining Greenhouse Gas Emissions for cites. http:// www.unep.org/urban_environment/PDFs/InternationalStd-GHG.p df.

Vaccari, F.P., Gioli, B., Toscano, P., and Perrone, C. (2013). Carbon dioxide balance assessment of the city of Florence (Italy), and implications for urban planning. Landscape Urban Plann., 120, 138-146. http://dx.doi.org/10.1016/j.landurbplan.2013.08.004

Wang, R., Tao, S., Ciais, P., Shen, H.Z., Huang, Y., Chen, H., Shen, G.F., Wang, B., Li, W., Zhang, Y.Y., Lu, Y., Zhu, D., Chen, Y.C., Liu, X.P., Wang, W.T., Wang, X.L., Liu, W.X., Li, B.G., and Piao, S.L. (2013). High-resolution mapping of combustion processes and implications for $\mathrm{CO}_{2}$ emissions.Atmos. Chem. Phys., 13, 5189-5203. http://dx.doi.org/10.5194/acp-13-5189-2013

Wang, J.N., Cai, B.F., Zhang, L.X., Cao, D., Liu, L.C., Zhou, Y., Zhang, Z.S., and Xue, W.B. (2014). High resolution carbon dioxide emission gridded data for China derived from point sources. Environ. Sci. Technol., 48, 7085-7093. http://dx.doi.org/10. 1021/es405369r

Zhang, L.X., Feng, Y.Y., and Chen, B. (2011). Alternative scenarios for the development of a low-carbon city: A case study of Beijing, China. Energies, 4, 2295-2310. http://dx.doi.org/10.3390/en41222 95

Zhang, L.X., Hu, Q.H., and Zhang, F. (2014). Input-output modeling for urban energy consumption in Beijing: Dynamics and comparison. PLOS ONE, 9(3): e89850. http://dx.doi.org/10.1371/ journal.pone.0089850

Zhang, L.X., Wang, C.B., and Bahaj, A.S. (2014).Carbon emissions by rural energy in China.Renewable Energy, 66, 641-649.http://dx. doi.org/10.1016/j.renene.2014.01.005

Zhao, R.Q. (2012). Carbon Cycle of Urban System and Its Regulation through Land Use Control, Nanjing University Press, Nanjing, China, pp: 2-23 (in Chinese).

Zhao, R.Q., and Huang, X.J. (2013). Carbon cycle of urban system: Characteristics, mechanism and theoretical framework. Acta Ecol. Sin., 33(2), 358-366 (in Chinese). http://dx.doi.org/10.5846/stxb20 1111121721

Zhao, R.Q., Huang, X.J., Zhong, T.Y., Liu, Y., and Chuai, X.W. (2014). Carbon flow of urban system and its policy implications: The case of Nanjing. Renew. Sustain. Energy Rev., 33, 589-601. http://dx.doi.org/10.1016/j.rser.2014.02.020 